\title{
Editorial
}

\section{Regulators on the run}

Pensions (2008) 13, 189-190. doi:10.1057/pm.2008.27

The financial meltdown in the autumn of 2008 and the credit crunch that preceded it have brought from some sectors a demand for additional regulation, while other commentators, some with few axes to grind, have suggested that this might be unhelpful. In fact, they add, it may be that the regulation itself has led to elements of the crisis. For, whatever the rules, bright guys in the City will find a way round them.

Now that is hardly a call for anarchy like the wild west before John Wayne cleaned it up. We need a system to protect the weak against the strong, to ensure the enforcement of contracts, to assist the widow and the orphan. We need to be comfortable that the milk we drink is free from $\mathrm{TB}$, the cars we drive will have brakes that work, and that our prisons are not dens of suppurating harshness - and regulations and regulators can do that for us as a society more efficiently than we can do it individually. But there is beginning to be a backlash against excessive regulation that demands the removal of flower holders on lamp posts lest we be decapitated in a strong wind, and the need to build a scaffold to replace a lamp in a church. And some regulation may simply be impossible to impose. In particular, it may be that in commercial and financial matters we may have to learn to live with booms and busts, with the roller coaster of capitalism, under law rather than under regulation.

This musing has been prompted by the revelation by the Financial Services Ombudsman that he has a staff of over 800 . The FSA, admittedly revised from time to time, first started over 20 years ago, and the cost to the financial services industry runs into the hundreds of millions, especially if the (incalculable) on-cost to consumers in the form of compliance officers' directives and the need to meet anti-moneylaundering requirements is taken into account. It is an immense enterprise, and in some ways there have been beneficial consequent changes. IFAs are slightly less aggressive than before, insurance companies are slightly less cynical than before and products are slightly less worse than before. But the fact that it still needs 800 people to deal with complaints (now that the surge following the pension mis-selling and the endowment misselling have gently passed by) shows that actually all those millions and all the visits by compliance officers added to the splendid art collection in Canary Wharf, may have been in vain. Part of the reason is that the policy makers may have forgotten the underlying premise of Professor Gower, in his report that led to the establishment of the FSA, that it was no duty of the law or of the regulators to prevent the proverbial foolish little old lady from making foolish decisions. There may need to be a limit to the protection of the consumer.

The question that the financial services community is now dealing with is whether despite the money spent, the fines imposed, the complaints system developed, the system has devoted its efforts to the minor rather than the major. And that maybe, first, nothing can be done in law or regulation to the natural human and natural cycle of feast and famine and that second, any regulation may do more harm than good. Human intervention has come in for some criticism by the green tendency in recent years but there is a consensus that dams can regulate floods, and contribute to power generation and crop irrigation at the same time. Regulation itself can control the excesses of the climate, and levees in St Louis might have if they had been big 
enough and strong enough defeated the effect of the hurricane, even if the hurricane itself was inevitable.

Biblical tradition also suggests that regulators can manage to save enough in feast times in the dominant country of the day to feed in famine times not only the dominant but also surrounding impoverished countries as well.

So there can be good things about planning and regulation. The question for policy makers over the next few rather dispiriting years will be whether we had the wrong sort of regulation, or whether we need more regulation, different regulation or probably less regulation in future. Less regulation might make the players slightly more cautious, and the investors also more keen to trust a little less. But they and we may have to accept there are tides in the affairs of man....

As in financial services, so perhaps in pensions regulation. It cannot be just a coincidence that regulation has increased at just the same time there has been a decline in provision, though as always in these matters it is unhelpful to look for a single cause. But we have a large regulator, and a diminishing sector to regulate. Maybe our legislators should face the fact that the usual checks and balances (the use of trusts and trustees, the power to enforce contracts by the courts) are sufficient although not perfect, and that regulation cannot prevent or even ameliorate failure, or perhaps regulation should have a different objective and maybe a diminished role. The two themes were connected by the failure of both Lehman Brothers, despite regulation by a plethora of regulators in the US and the UK working in investment sectors (ie financial products and mortgages) that are intensively controlled in both jurisdictions, and Lehman Brothers pension scheme, less intensively regulated by the pension regulators, and which other pension funds will have to pay for, including very substantial pensions of very rich people. It all seems rather odd.
Other countries have consumer protection 'lite'; and it may be time to explore whether that might suit us more. To try and prevent a systemic meltdown may be all but impossible; life is full of jubilees. What we might need to do is to accept that, mention the risk to consumers, and implement simple remedies and balances to cope with things while the next catastrophe arises.

What regulators and legislators are very bad at doing is predicting the next meltdown, and in pensions that is a hard one to call even for those who know about the issues.

In the meantime, those who enjoy schadenfreude (and that is most of us) will continue to watch the sight of bankers selling houses - and eventually (perhaps in a year or two) considering why, despite all the efforts of corporate governance gurus and remuneration committees the guys with yachts and jets are still sailing and flying with money that they have all but stolen from the community while our backs were turned. All those pension schemes with LDI strategies, which were perhaps less than well understood, will be reflecting that swaps make uneasy bedfellows in times when counterparties flee like bats in the night. We have all learnt a lesson from the conflagration; but we and our children will forget it next time round - as we will the uncomfortable facts that the sub-prime mortgages were encouraged and sometimes prescribed by US law, and securitisation designed to isolate just the risks that refused to go away. The old nostrums remain as valid as ever: if you don't understand it, don't do it. Inflation is sleeping not dead. And regulation always fights the last war (George, 2008).

\section{Robin Ellison ${ }^{1}$ \\ ${ }^{1}$ E-mail: Robin.Ellison@pinsentmasons.com}

\section{References}

George, E. (2008) 'Banking on stability: A framework for economic success'. Politeia. 